\title{
Koroziv madde hasarlarının retrospektif olarak değerlendirilmesi
}

\author{
Retrospective evaluation of corrosive injuries
}

Seyit UYAR ${ }^{1}$, Süleyman DOLU ${ }^{1}$, Mehmet KÖK ${ }^{1}$, Gökhan KÖKER ${ }^{1}$, Mutlu ÇATLI ${ }^{1}$, Feyzi BOSTAN ${ }^{1}$, Yasin ŞAHINTTÜRK ${ }^{1}$, Ayhan Hilmi ÇEKIN ${ }^{2}$

Antalya Eğitim ve Araştırma Hastanesi, ${ }^{1}$ Iç Hastalıkları Kliniği, ${ }^{2}$ Gastroenteroloji Kliniği, Antalya

\begin{abstract}
Giriş ve Amaç: Koroziv madde alımı çoğunlukla pediatrik popülasyonda yanlışsıkla içim sonrası görülse de, erişkin yaş grubunda da hala karşılaşıın bir durumdur. Oluşabilecek hasar içilen maddenin cinsi, miktarı ve mukoza ile temas süresi ile doğrudan ilgilidir. Hasarın erken tespit edilmesi tedavinin en önemli basamağıdır ve endoskopik görüntüleme bu konudaki en önemli yöntemdir. Biz bu çalışmada hastanemize başvurmuş olan erişkin yaş koroziv madde alımlarını retrospektif olarak değerlendirmek istedik. Gereç ve Yöntem: 01 Ocak 2008 ve 01 Temmuz 2017 ylları arasinda koroziv madde alımı ile hastanemize bassvuran, 18 yas üstü 125 vaka çalıșmaya dahil edildi. Hastaların endoskopik hasar derecesi 0-1-2 olanlar hafif, 3-4 olanlar ciddi hasar olarak değerlendirildi. Içilen maddeler özelliklerine göre asidik, alkali ve diğer olarak gruplandı.. Bulgular: 62 kadın, 63 erkek toplam 125 hastanın yaş ortalaması 39,3 $\pm 15,1$ yıl idi. 90 hastaya (\%72) ilk 24-48 saat içinde endoskopi yapılmıştı. 95 hasta (\%76) maddeyi yanlışlıkla, 30 hasta (\%24) ise suisid amaçlı almıştı. 14 (14,7) hastada özofagus, 43 (\%45,3) hastada mide ve 38 (\%40) hastada mide ve özofagus beraber tutulmuştu. Hastalarin 84'ünde $(\% 67,2)$ hafif hasar (grade 0-1-2) ve 11 'inde $(\% 8,8)$ ciddi hasar (grade 3-4) vardı. Asidik madde alanlarda hasar oranı ve yaygin tutulum (özofagus ve mide) alkali alanlara göre daha fazla izlendi. Sonuç: Hastaların yaklaşık 2/3'üne endoskopi literatürde önerildiği șekilde, ilk 24-48 saat içinde yapılmıştı. Bilinenin aksine bizim çalışmamızda asidik maddeler hem daha fazla hasara hem de daha yaygın bir tutuluma neden olmuşlardır. $\mathrm{Bu}$ nedenle asidik madde alan hastalar da dikkatli izlenmeli ve gereken tedaviler vakit kaybedilmeden yapılmalıdır
\end{abstract}

Anahtar kelimeler: Koroziv alımı, koroziv hasarlanma, özofagus, mide
Background and Aims: Even though corrosive ingestion was primarily detected accidentally in children, it is still found in the adult age group. The injury that can occur is directly related to the type, quantity, and duration of contact of the ingested material with the mucosa. Early detection of injury is the most important step in the treatment, and endoscopic imaging constitutes the most important method in this regard. In this study, a retrospective evaluation of corrosive injuries was conducted among the adult population. Materials and Methods: This study included a total of 125 patients aged more than 18 years who were admitted to our hospital with corrosive ingestion between January 01, 2008 and July 01, 2017. On the basis of the endoscopic findings, patients with grade 0-1-2 injuries were considered as those with mild injury and patients with grade 3-4 injuries were considered as those with severe injury. Corrosive substances were categorized as acidic, alkali, and others according to their properties. Results: The mean age of the 125 patients (62 females; 63 males) was $39.3 \pm 15.1$ years. Endoscopy was performed in the first 24-48 h in 90 patients (72\%). A total of 95 patients (76\%) accidentally ingested the substance, whereas 30 patients (24\%) intentionally did so. Involvement was only esophageal in 14 (77.4\%) patients, only gastric in $43(45.3 \%)$ patients, and both gastric and esophageal in $38(40 \%)$ patients. Mild damage (grade 0-1-2) was found in 84 (67.2\%) patients, and severe damage (grade 3-4) was detected in 11 (8.8\%) patients. The rate of damage and widespread involvement (both esophageal and gastric in acidic substance ingestions were higher than that in alkaline substance ingestions. Conclusion: Approximately two-thirds of the patients underwent endoscopy in the first 24-48 h in accordance with the literature. In contrast with the literature, our study findings state that acidic substances caused both more damage and more extensive involvement. Therefore, patients who have ingested acidic substances should be carefully monitored and treated.

Key words: Corrosive ingestion, corrosive injury, esophagus, stomach

nemde özofagusta ve midede darlıklar, hiatus hernisi, malignite gelişimi gibi kronik komplikasyonlar gelişebilir (4). Üst gastrointestinal sistem endoskopisi oluşabilecek erken hasar1 tespit etmenin en iyi yöntemidir ve endoskopik bulgular da gelişebilecek geç komplikasyonları tahmin etmenin majör belirleyicisidir. Özofagogastroduedonoskopinin (ÖGD) genellikle koroziv madde alımı sonrası ilk 12-48 saat içinde yapılması önerilse de, 96. saate kadar güvenli bir şekilde uygulanabilir (3). Mukoza çok hassas olduğu için, oluşabilecek komplikasyonlardan dolayı işlem boyunca çok nazik olunmalı ve büyük bir özen gösterilmelidir. Zargar ve ark. tarafından oluşturulan endoskopik sınıflama (Tablol) tedavi 
Tablo 1. Koroziv madde hasarmda endoskopik siniflama

\begin{tabular}{|ll|}
\hline Derece & Özellik \\
\hline Grade 0 & Normal \\
\hline Grade 1 & Yüzeyel, mukozal ödem ve eritem \\
\hline Grade 2A & Yüzeyel ülserler, erozyonlar ve eksuda \\
\hline Grade 2B & Derin ayrık ya da dairesel ülserler \\
\hline Grade 3A & Fokal nekroz \\
\hline Grade 3B & Yaygın nekroz \\
\hline Grade 4 & Perforasyon \\
\hline
\end{tabular}

ve prognozu belirlemede kullanılan en önemli parametredir (5). Bazı laboratuvar testleri (lökosit sayısı, C-reaktif protein, arter kan gazı), bilgisayarlı tomografi ve endoskopi ultrasonografi de bazı çalışmalarda koroziv hasarın teşhisi ve prognoz açısından kullanılmış olsa da endoskopinin yerine geçememişlerdir (6).

Genel olarak koroziv maddeler alkali ya da asit olarak değerlendirilirler. Alkali maddeler daha çok batı toplumlardaki hasarlanmalara neden olurken, asidik maddeler gelişmekte olan ülkelerde koroziv hasara yol açarlar (7). Alkali maddeler daha yoğundurlar ve bu nedenle özofagusta daha uzun süre kalırlar. Bu maddeler doku proteinleri ile birleșerek likefaksiyon nekrozu ve saponifikasyona (sabunlaşmaya) neden olur ve böylece daha derin dokulara penetre olurlar. Ayrıca dokulara alkali absorbsiyonu nedeniyle vasküler tromboz oluşturabilirler (8). Asitli maddeler ise genellikle orofaringeal bölgede ağriya neden olduğu için fazla miktarda içilemez ve yoğunluğu alkali maddelere göre daha düşük olduğu için hızlı bir şekilde mideye geçerler (1). Bu maddeler süperfisiyal koagülasyon nekrozuna yol açar ve oluşan skar nedeniyle alkali maddeler kadar derin hasar oluşturmazlar (9). Ozofagusta oluşan bu skar dokusunun koruyuculuğu nedeniyle de asitli maddelerin daha çok midede hasar oluşturduğu kabul edilir. Koroziv madde alımından hemen sonra hasarlanma başlar. Genellikle 10. günden sonra özofageal iyileşme dönemi, yaklaşık 1 ay sonra da ülserlerde epitelizasyon oluşmaya başlar (3). Bu nedenle 5. ve 15. günler arasinda ÖGD yapmaktan kaçınılmalıdır (5). Başlayan bu iyileşme süreci aylarca devam edebilir. Bu nedenle hastalar oluşabilecek komplikasyonlar açısından belli aralıklarla kontrol edilmelidir.

Erişkin popülasyonda koroziv madde alımı ülkemizde de hala karşılaşılan bir durumdur. Biz bu çalışmada, bu konudaki klinik deneyimlerimizi ve endoskopi yapılan hastaların sonuçlarını incelemeyi amaçladık.

\section{GEREC ve YÖNTEM}

01 Ocak 2008 ve 01 Temmuz 2017 tarihleri arasında hastanemize koroziv madde içme şikayeti ile başvuran 18 yaş üstü hastalar retrospektif olarak tarandı. Hastaların demografik

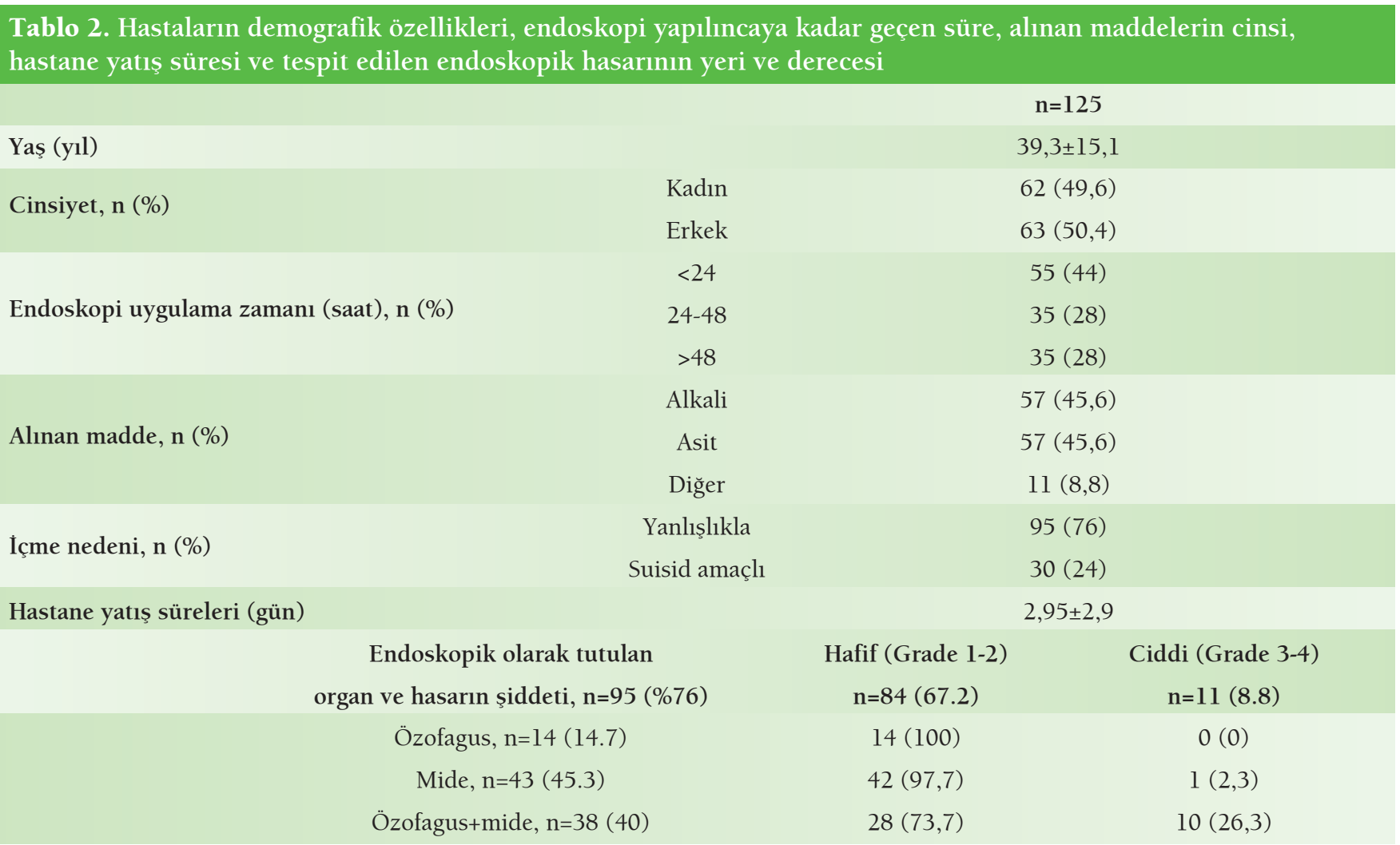


verileri, içilen maddenin cinsi ve miktarı, endoskopi yapılma zamanı, endoskopik bulgu ve hastane yatış süreleri hasta dosyalarından incelendi. Hastaların endoskopik hasar derecesi grade 0-1-2 olanlar hafif, grade 3-4 olanlar da ciddi olarak gruplandı (10). Endoskopi yapılamamış olan hastalar çalışmaya dahil edilmedi. Sodyum hidroksit, potasyum hidroksit, sodyum karbonat, amonyak, amonyum hidroksit, sodyum hipoklorit içeren ve sodyum fosfat içeren çamaşır suyu ve çeşitli yüzey temizleyiciler alkali, sülfürik asit, oksalik asit, hidroklorik asit ve fosforik asit içeren kireç çözücü ve çeşitli temizleyici maddeler de asidik olarak kabul edildi. Tiner nötr olduğu için ve içtiği maddeyi bilmeyen kişiler de diğerleri olarak değerlendirildi. Çalışma etik kurul onayı hastanemiz etik kurulundan alındı ve çalışma prosedürü Helsinki Deklerasyonuna uygun olarak yapildı.

\section{İstatistik analizler}

Tanımlayıcı istatistikler frekans, yüzde, ortalama, standart sapma (SS) ve medyan, minimum (min), maksimum (max) değerleri ile sunulmuştur. Kategorik değişkenler arasındaki ilişkilerin analizinde Fisher's Exact Test veya Pearson ki-kare testi kullanılmıştır. Normallik testinde gruptaki örneklem sayıs1 50'den küçük olduğunda Shapiro Wilks, büyük oldugunda Kolmogorov-Smirnov testi kullanılmıştır. Iki grubun ölçüm değerleri arasındaki farkın analizinde normallik varsayımının sağlanmadığı durumlarda Mann-Whitney U testi, sağlandığı durumlarda Student t testi kullanılmıştır. Analizler SPSS 21.0 paket programı ile yapılmıştır. 0,05'den küçük p değerleri istatistiksel olarak anlamlı kabul edilmiştir.

\section{BULGULAR}

Çalışmamızda toplam 125 hasta (62 kadın, 63 erkek) retrospektif olarak değerlendirildi. Hastaların yaş ortalaması $39,3 \pm 15,1$ yll idi. Hastaların 55 'ine (\%44) ilk 24 saat içinde, 35 'ine (\%28) 24-48 saat arasinda ve kalan 35'ine de (\%28) 48. saatten sonra endoskopi yapılmıştı. Hastaların ortalama hastanede yatış süreleri $2,95 \pm 2,9$ gündü. 57 hasta $(\% 45,6)$ alkali, 57 hasta $(\% 45,6)$ asit ve kalan 11 hasta da $(\% 8,8)$ iki

Tablo 3. İçilen maddenin cinsine ve hasarın șiddetine göre verilerin karşılaștırılması

\begin{tabular}{|c|c|c|c|c|}
\hline & & Alkali, $\mathrm{n}=57$ & Asidik, $\mathrm{n}=57$ & $\mathrm{p}$ \\
\hline Yaş (yıl), ort $\pm S S$ & & $36,2 \pm 14,9$ & $42,3 \pm 15,1$ & 0,033 \\
\hline \multirow{2}{*}{ Cinsiyet, n (\%) } & Erkek & $28(49,1)$ & $29(50,9)$ & \multirow{2}{*}{0,851} \\
\hline & Kadın & $29(50,9)$ & $28(49,1)$ & \\
\hline $\begin{array}{l}\text { Hastane yatış süresi, } \\
\text { medyan (min-max) }\end{array}$ & & $2(1-10)$ & $2(1-21)$ & 0,001 \\
\hline \multirow{3}{*}{ Endoskopik hasar, n (\%) } & Hasar yok & $23(40,4)^{\mathrm{a}}$ & $4(7)^{b}$ & \multirow{3}{*}{$<0,001$} \\
\hline & Hafif & $33(57,9)^{\mathrm{a}}$ & $44(77,2)^{b}$ & \\
\hline & Ciddi & $1(1,8)^{\mathrm{a}}$ & $9(15,8)^{b}$ & \\
\hline \multirow{4}{*}{ Organ tutulumu, n (\%) } & Tutulum yok & $23(40,4)^{\mathrm{a}}$ & $4(7)^{b}$ & \multirow{4}{*}{$<0,001$} \\
\hline & Özofagus & $6(10,5)^{a}$ & $7(12,3)^{a}$ & \\
\hline & Mide & $23(40,4)^{\mathrm{a}}$ & $17(29,8)^{\mathrm{a}}$ & \\
\hline & Özofagus+mide & $5(8,8)^{a}$ & $29(50,9)^{\underline{b}}$ & \\
\hline & & $\begin{array}{l}\text { Hafif hasar (Grade 1-2) } \\
\qquad \mathrm{n}=84\end{array}$ & $\begin{array}{l}\text { Ciddi hasar (Grade 3-4) } \\
\mathrm{n}=11\end{array}$ & \\
\hline Yaş (yıl), ort $\pm S S$ & & $40,6 \pm 14,9$ & $45,4 \pm 13,2$ & 0,318 \\
\hline \multirow{2}{*}{ Cinsiyet, $\mathrm{n}(\%)$} & Erkek & $44(52,4)$ & $6(54,5)$ & \multirow{2}{*}{0,892} \\
\hline & Kadın & $40(47,6)$ & $5(45,5)$ & \\
\hline $\begin{array}{l}\text { Hastane yatış süresi, } \\
\text { medyan (min-max) }\end{array}$ & & $2(1-7)$ & $8(4-21)$ & $<0,001$ \\
\hline \multirow{2}{*}{ İçme nedeni, n (\%) } & Yanlışlıkla & $65(77,4)$ & $7(63,6)$ & \multirow{2}{*}{0,453} \\
\hline & Suisid amaçlı & $19(22,6)$ & $4(36,4)$ & \\
\hline \multirow{3}{*}{$\begin{array}{l}\text { Endoskopi uygulama zamanı } \\
\text { (saat), n (\%) }\end{array}$} & $<24$ & $38(45,2)$ & $3(27,3)$ & \multirow[t]{3}{*}{-} \\
\hline & $24-48$ & $25(29,8)$ & $4(36,4)$ & \\
\hline & $>48$ & $21(25)$ & $4(36,4)$ & \\
\hline \multirow{3}{*}{ Organ tutulumu, n (\%) } & Özofagus & $14(16,7)$ & $0(0)$ & \multirow[t]{3}{*}{-} \\
\hline & Mide & $42(50)$ & $1(9.1)$ & \\
\hline & Özofagus+mide & $28(33,3)$ & $10(90.9)$ & \\
\hline
\end{tabular}


gruba da girmeyen madde almıştı 95 hasta (\%76) maddeyi yanlışlıkla, 30 hasta (\%24) ise suisid amaçlı almıştı. 30 (\%24) hastanın endoskopisinde tutulum tespit edilmemişti. Kalan $95(\% 76,4)$ hastanın 14'ünde $(14,7)$ özofagus, 43 'ünde $(\% 45,3)$ mide ve 38 'inde (\%40) mide ve özofagus beraber tutulmuştu. Hastaların 84'ünde $(\% 67,2)$ hafif hasar (grade 0-12) ve 11 'inde $(\% 8,8)$ ciddi hasar (grade 3-4) vardı (Tablo 2).

Alkali madde alan toplam 57 hastanın (29 kadın, 28 erkek) ortalama yaşı $36,2 \pm 14,9$ yll, asidik madde alan 57 hastanın (28 kadın, 29 erkek) ortalama yaşı ise $42,3 \pm 15,1$ yl idi. tki grup arasında cinsiyet açısından fark yok $(p=0,851)$, yaş açısindan anlamlı istatistiksel fark mevcuttu $(\mathrm{p}=0,033)$. Hastaların medyan hastanede yatış süreleri alkali içenlerde 2 (110) gün, asit içenlerde 2 (1-21) gündü $(\mathrm{p}=0,001)$. Yapılan endoskopilerde alkali içenlerin 23 'ünde $(\% 40,4)$ organ tutulumu yok, 33 kişide $(\% 57,9)$ hafif hasar ve 1 kişide $(\% 1,8)$ ciddi hasar, asit içenlerin ise 4'ünde (\%7) tutulum yok, 44 kişide $(\% 77,2)$ hafif hasar ve 9 kişide $(\% 15,8)$ ciddi hasar mevcuttu $(\mathrm{p}<0,001)$. Hasar oluşan organlara bakıldığında ise; alkali içenlerin 6'sında (\%10,5) özofagus, 23 kişide $(\% 40,4)$ mide, 5 kişide $(\% 8,8)$ özofagus ve mide beraber, asit içenlerin de 7 'sinde $(\% 12,3)$ özofagus, 17 kişide $(\% 29,8)$ mide ve 29 kişide $(\% 50,9)$ özofagus ve midede hasar oluşumu vardı $(\mathrm{p}<0,001)$ (Tablo 3).

Hafif hasarlı toplam 84 hastanın (40 kadın, 44 erkek) ortalama yaşı 40,6 $\pm 14,9$ yll, ciddi hasarlı toplam 11 hastanın (5 kadın, 6 erkek) ortalama yaşı 45,4 $\pm 13,2$ yıldı ve iki grup arasında yaş ve cinsiyet açısından fark yoktu. Hastaların medyan hastanede yatış süreleri hafif hasarlılarda 2 (1-7) gün, ciddi hasarlılarda $8(4-21)$ gündü $(\mathrm{p}<0,001)$. Hafif $[65(\% 77,4)$ kişi yanlışlıkla, $19(\% 22,6)$ kişi suisid amaçlı] ve ciddi hasar [7 $(\% 63,6)$ kişi yanlışlıkla, $4(\% 36,4)$ kişi suisid amaçl1] oluşumunda yanlışlıkla içen hastalar ve suisidal amaçla içenler arasında fark yoktu $(\mathrm{p}=0,453)$. Hastaların endoskopi yapılma zamanı ve organ tutulumları arasinda, hafif ve ciddi hasarlı gruplar arasında istatistiksel karşılaştırma yapılamamıştır (Tablo 3).

\section{TARTISSMA}

Hastanemize 2008 ve 2017 ylları arasında, koroviz madde alımı tanısıyla yaş ortalaması 39,3 yıl olan toplam 125 erişkin hasta başvurusu mevcuttu. Bu durum ülkemizde hala koroziv hasarının önemli ölçüde devam ettiğini göstermekte ve güncel bir konu olarak ele alınmasını gerektirmektedir. Hastaların \%72'sine endoskopi ilk 48 saat içinde yapılmıştı. Endoskopinin zamanlaması ile ilgili literatürde tartışma hala devam etmektedir. Poley ve ark. ilk 24 saat içinde yapılan endoskopideki bulgunun tedavi planını belirlediğini belirtmişlerdir (11). 2008 yılında bir çalışma da ise Cheng ve ark. ilk 12 saat içinde yapılan endoskopinin mukozal hasarı daha iyi tespit edebileceğini belirtmiştir (12). Başka bir çalışmada da mümkün olduğunca erken yapılan endoskopinin tedavi- nin temel noktası olduğu belirtilmiştir (10). Koroziv alımında hasarın şiddeti alınan maddenin cinsine, miktarına ve mukoza ile temas süresi ile ilişkilidir (13). Bizim çalışmamızda alınan maddelere bakıldığında 11 madde nötr ya da ne içildiği bilinmeyen, geri kalanların ise yarısı alkali madde yarısı da asidik maddeydi. 95 kişi yanlışlıkla, 30 kişi ise suisid amaçlı koroziv almıștı. Hastalarımızın ortalama hastanede yatırılma süresi 3 gündü. 30 hastanın endoskopisi normal, $84(\% 67,2)$ hastada hafif hasar (grade $1-2)$ ve $11(\% 8,8)$ hastada ciddi hasar (grade 3-4) mevcuttu. Cheng ve ark.'nın 2008 yllında Tayvan'da yaptığı retrospektif çalışmada 273 koroziv alımı incelenmiş ve hastaların \%44'ünde ciddi hasar görülmüştür (12). Bu çalışmada sadece 3 (\%1) hastanın endoskopisi normal bulunmuş ve bu durum çoğunluğun intihar amaçlı maddeyi almasına bağlanmış. Bizim taramamızda yanlışlıkla alımlar çoğunluğu oluşturduğu için, iki çalışma arasındaki farklılık alım nedenine bağlanabilir.

Alınan maddenin asidik ya da alkali olması durumuna göre hastaları karşılaştırdığımızda; alkali madde içenlerde hasar olmama yüzdesi asidik madde içenlere göre daha yüksek iken, asidik madde içenlerde ise hem hafif hem de ciddi hasar görülme yüzdesi alkalilere göre istatistiksel olarak daha yüksektir. Ayrıca, alkali madde içenlerde tutulum olmama yüzdesi asidik madde içenlere göre daha yüksek iken, asidik madde içenlerde tutulumun özofagus ve midede beraber görülme yüzdesi alkalilere göre istatistiksel olarak daha yüksekti. Bu durum genel literatür bilgisi olan asitli maddelerin daha hafif hasar oluşturduğu (9) bilgisi ile tezat oluşturmaktadır. Çalışmamızda asidik madde alanların medyan hastanede kalış süresi de alkali alanlara göre anlamlı olarak yüksek bulundu. Hastaların hasar derecesine göre yaş ve cinsiyet açısından fark yoktu.

Bu çalışmada prospektif çalışma yapma imkanı olmayan bir durum olan koroziv madde hasarını retrospektif olarak değerlendirdik ve verilerimizi paylaştık. Alınan maddenin bazılarının bilinememesi ve içilen miktarın belirtilmemesi çalışmamızın kısıtllıklarından sayılabilir. Ciddi hasarlı hastaların sayısının az olması nedeniyle tutulan organ ve endoskopi uygulama zamanında karşılaştırma yapılamaması da diğer bir kısıtlllık olarak belirtilebilir.

Koroziv madde alımı geri dönüşsüz mide ve/veya özofagus hasarına yol açabilen bir durum olarak hala klinisyelerin karşısına çıkmaktadır. Alınan maddenin cinsine, alınma nedenine, miktarına ve hastanın klinik durumuna göre hastalara ilk değerlendirilme yapılmalı ve 24-48 saat içinde endoskopi yapılması planlanmalıdır. Endoskopi tanı, tedavi ve prognoz açısından en önemli diyagnostik yöntem olmaya devam etmektedir. Bilinenin aksine bizim çalışmamızda asidik maddeler hem daha fazla hasara hem de daha yaygin bir tutuluma neden olmuşlardır. Bu nedenle asidik madde alımları da göz ardı edilememelidir. 


\section{KAYNAKLAR}

1. Koçak E. Özofagus'un acil problemleri. Endoskopi 2010;18:46-51.

2. Gumaste VV, Dave PB. Ingestion of corrosive substances by adults. Am J Gastroenterol 1992;87:1-5.

3. Contini S, Scarpignato C. Caustic injury of the upper gastrointestinal tract: a comprehensive review. World J Gastroenterol 2013;19:3918-30.

4. Karaoğlu AÖ, Özütemiz Ö, Ilter T, Batur Y, Yönetçi N, Tekeşin O. Caustic ingestion injuries: evaluation of 108 cases. Turk J Gastroenterol 1998;9:55-60.

5. Zargar SA, Kochhar R, Mehta S, Mehta SK. The role of fiberoptic endoscopy in the management of corrosive ingestion and modifiedendoscopic classification of burns. Gastrointest Endosc 1991;37:165-69.

6. Uyar S, Kök M. Neutrophil to lymphocyte ratio as a predictor of endoscopic damage in caustic injuries. J Clin Toxicol 2017;7: Doi: 10.4172/2161-0495.1000349

7. Zargar SA, Kochhar R, Nagi B, Mehta S, Mehta SK. Ingestion of corrosive acids. Spectrum of injury to upper gastrointestinal tract and natural history. Gastroenterology 1989;97:702-7.
8. Mamede RC, de Mello Filho FV. Ingestion of caustic substances and its complications. Sao Paulo Med J 2001;119:10-5.

9. Havanond $\mathrm{C}$. Is there a difference between the management of grade $2 \mathrm{~b}$ and 3 corrosive gastric injuries? J Med Assoc Thai 2002;85:340-4.

10. Cabral C, Chirica M, de Chaisemartin C, et al. Caustic injuries of the upper digestive tract: a population observational study. Surg Endosc 2012;26:214-21

11. Poley JW, Steyerberg EW, Kuipers EJ, et al. Ingestion of acid and alkaline agents: outcome and prognostic value of early upper endoscopy. Gastrointest Endosc 2004;60:372-7.

12. Cheng HT, Cheng CL, Lin CH, et al. Caustic ingestion in adults: the role of endoscopic classification in predicting outcome. BMC Gastroenterol 2008;8:31.

13. Goldman LP, Weigert JM. Corrosive substance ingestion: a review. Am J Gastroenterol 1984;79:85. 